Satisfaction with information about ionising radiation: a comparative study in Belgium and France

This content has been downloaded from IOPscience. Please scroll down to see the full text.

2016 J. Radiol. Prot. 36 S122

(http://iopscience.iop.org/0952-4746/36/2/S122)

View the table of contents for this issue, or go to the journal homepage for more

Download details:

IP Address: 146.175.11.111

This content was downloaded on 01/07/2016 at 09:22

Please note that terms and conditions apply. 


\title{
Satisfaction with information about ionising radiation: a comparative study in Belgium and France
}

\author{
C O Turcanu ${ }^{1}$, M-H El Jammal ${ }^{2}$, T Perko $^{1}$, G Baumont ${ }^{2}$, \\ E Latré ${ }^{1,3}$ and I Choffel de Witte ${ }^{2}$ \\ ${ }^{1}$ SCK $\bullet C E N$, Belgian Nuclear Research Centre, Mol, Belgium \\ ${ }^{2}$ Institut de Radioprotection et de Sûreté Nucléaire, IRSN, Fontenay-aux-Roses, \\ France \\ ${ }^{3}$ University of Antwerp, Antwerp, Belgium \\ E-mail: cturcanu@sckcen.be
}

Received 30 September 2015, revised 8 February 2016

Accepted for publication 3 March 2016

Published 6 June 2016

\begin{abstract}
In recent decades efforts have been made to meet societal expectations concerning public access to information and to enable citizens' informed decision-making related to ionising radiation risks. But are people satisfied with the information provided and which factors influence this? This paper investigates lay persons' satisfaction with the information about ionising radiation provided by different communicators in Belgium and France. In particular, it studies the potential influence of risk perception, confidence in authorities, knowledge and education. The study is based on data originating from large scale public opinion surveys $(N=1002$ in Belgium; $N=966$ in France). Results show that the two countries differ as regards satisfaction with the information provided by specific communicators. Confidence in authorities was revealed in both countries as more important for satisfaction with information than risk perception. Contrary to expectations, general knowledge about ionising radiation had limited or no explanatory power. An additional study for the Belgian sample showed that both perceived trustworthiness and technical competence influence satisfaction with information, but their relative importance depends on the communicator.
\end{abstract}

Keywords: public communication, risk perception, confidence, trust, knowledge, ionising radiation information

(Some figures may appear in colour only in the online journal) 


\section{Introduction}

Communication about ionising radiation and its applications, as well as the related benefits and risks is not only a prerequisite of nowadays democratic society in the context of public access to information, but also a tool enabling public participation in the context of nuclear activities and informed decision-making (OECD 2004, Gadbois et al 2007). Legal instruments have been developed to enable public access to information and citizens' participation in decision-making on environmental and health issues, for instance the Aarhus Convention on Access to Information, Public Participation in Decision-making and Access to Justice in Environmental Matters (UNEC 1998) or the European Directive on Environmental Impact Assessment and Strategic Environmental Assessment (EU 2001).

In the medical field, patients' exposure to ionising radiation in medical examinations is increasingly the subject of controversy. Previous research showed that patients are insufficiently informed about the issue (Nickoloff and Alderson 2001, Lee et al 2004). The European Council Directive 2013/59/Euratom (Euratom 2013) laying down basic safety standards for protection against the dangers arising from exposure to ionising radiation emphasizes the need for justification of medical exposure and for strengthening the requirements concerning information to be provided to patients.

With the increased public concern about technological risks, there has been a gradual 'shift in the public expectations from one-way communication to participation and dialogue between a plurality of stakeholders' in the context of nuclear activities (Gadbois et al 2007). Parallel to this, Peters et al (1997) pointed out an institutional shift: while public trust in traditional institutions such as the government and the industry declined, public trust in citizen associations such as environmental groups increased.

Various actors communicate about risks and benefits of ionising radiation, for example the nuclear industry, the nuclear control authorities, medical personnel and journalists. But is the public satisfied with the information provided by these communicators? What are the factors underlying their satisfaction with the information?

Media play an important role in risk communication (Lichtenberg and MacLean 1991) as they provide an efficient tool allowing communicators to reach large audiences. However, media do not only serve as a channel; they are also important communicators as they interpret and frame risk related information, process known as 'media construction of reality' (Wilson 1996, Kovach and Rosenstiel 2007, Berkowitz 2008).

In addition to media, other communication means (e.g. websites, leaflets, public meetings, etc) are also used to target specific audiences such as people living in the vicinity of nuclear installations or waste repositories, or patients exposed to ionising radiation from medical examinations.

Despite efforts towards increased public communication by all actors in the nuclear field, European citizens feel insufficiently informed about nuclear energy and radioactivity. For instance, a large majority of 75\% in Belgium and 79\% in France (Eurobarometer 324 2010) are rather unfamiliar (not very well informed or not informed at all) with safety issues related to Nuclear Power Plants. Also in terms of information about energy choices, including nuclear energy, satisfaction with information is rather low. The Eurobarometer 324 (2010) revealed that only 39\% in Belgium and 36\% in France considered the information provided by media as sufficient to form an informed opinion.

A number of previous studies in the literature investigated socio-economic determinants for the satisfaction with the information provided by actors in the nuclear field, notably related to radioactive waste disposals (Kari et al 2010, Kojo et al 2010). Another domain in which the topic received high attention is medicine, specifically on patient satisfaction with medical 
information (e.g. Verkissen et al 2014). Satisfaction with information was also studied is interpersonal communication (Hecht 1978, and subsequent studies based on it).

This paper investigates lay persons' satisfaction with the information about ionising radiation as provided by different communicators: the nuclear safety authorities, the medical doctors, the industry and the media. In particular, it studies the potential influence of risk perception, confidence in authorities, knowledge and education. In order to evaluate whether the same models are valid in two different countries, Belgium and France were taken as casestudies. For the Belgian case the effect of communicator trustworthiness and competence on the satisfaction with information was also tested. The interest in comparing the two countries is twofold. On the one hand, the two countries have similar communication culture and legal basis related to radiological risk governance. On the other hand, the countries have different nuclear energy policy: in Belgium the current legislation foresees the phase out of nuclear energy by 2025, whereas in France, who derives currently about $75 \%$ of its electricity from nuclear energy, the new energy policy as described in the new Energy Transition for Green Growth bill foresees only that this share is to be reduced to $50 \%$ by 2025 . Educational programs of the two countries also differ, concerning the basic knowledge on the nuclear topic. These differences and similarities may directly or indirectly affect people's satisfaction with the information.

The study was performed in the framework of the European FP7 project EAGLE ${ }^{4}$. This project aims at clarifying information and communication strategies that enable informed societal decision-making. EAGLE engages stakeholders in assessing the current dissemination of information about ionising radiation to the public and provides guidance tools for good practice supporting the ideal of participative, citizen-centred communication.

The remainder of the paper is organised as follows. The next section illustrates examples of communication channels and tools used by different actors to communicate about ionising radiation. Section 3 summarises previous research and formulates the research hypotheses of this study. Subsequently, several models are built to investigate potential predictors for the satisfaction with public information on ionising radiation provided by different communicators. Finally, the results obtained are discussed in section 5 and conclusions are formulated in section 6

\section{Communication about ionising radiation in Belgium and France-some examples}

In this section some examples are given to illustrate public communication about ionising radiation in both countries of interest by the nuclear communicators considered in this study.

In Belgium as well as in France, the information provision and public participation related to radiological risks are organised according to international legal instruments described in the introduction (e.g. the Aarhus Convention on Access to Information, Public Participation in Decision-making). While the main communicator related to radiological risks in Belgium is the Federal Agency for Nuclear Control (FANC), in France communication is mainly driven by two bodies: an independent technical safety organisation (IRSN) and the regulatory body (ASN). The aims of these communicators in Belgium and France are the same: to communicate in a transparent, neutral and objective manner about all health and environmental aspects related to ionising radiation. The importance of addressing the governance of radiological risks as a process of 'communicating with society', instead of merely 'informing society', is recognised and applied in both countries at different levels for the various domains and

\footnotetext{
${ }^{4}$ http://eagle.sckcen.be/en
} 
usage of ionising radiation, from information provision, to different levels of a stakeholders' engagement.

In Belgium for instance, communication about low level nuclear waste is developed to the level of stakeholder's engagement and inclusive risk governance (Laes and Bombaerts 2008), while public debate in the case of high level waste remains limited (Schröder et al 2015). A number of consultations, citizens' conferences, public meetings and open door days have been organised in order to continue information provision and citizens' participation in nuclear waste management focusing on nuclear waste disposals. These activities were organised by different actors, e.g. the nuclear waste agency (NIRAS/ONDRAF), local communities (MONA, STORA), universities or hired independent facilitators. Pluralistic approaches to nuclear waste communication are applied also in France.

Related to communication about nuclear emergencies, the two countries use similar approach. In compliance with the Nuclear Transparency Law, all research and expertise reports, reports on incidents or events which occurred on the nuclear plant or installation, but also all inspection notifications on nuclear installations are published on different websites in France. IRSN and ASN promote these reports and publications through press conferences and nowadays also through twitter. The local official called Prefecture organises informative campaigns to promote 'safety recommendations' and the preventive distribution and use of the stable iodine tablets for the people living nearby nuclear installations. In addition to the traditional structures, independent local information committees (CLI) and the Supreme Committee for Transparency were also established. The CLI are pluralistic bodies set next to every nuclear installation to inform the local population regarding nuclear safety and radiation protection. In Belgium, regular information campaigns on nuclear emergencies are conducted by FANC and the Ministry of Internal Affairs; prior to this study, such campaigns were organised in 1999, 2002 and in 2011. Traditional and social media, as well as personal communication and meetings with the population (Perko et al 2013) were used as information channels to communicate about nuclear installations, radioactivity and protective actions in case of a nuclear accident, with a focus on the preventive distribution and use of stable iodine tablets.

Belgian and French authorities communicate regularly also about radon. While in Belgium communication efforts target only the population where radon concentration in houses constitutes a problem by using printed media ${ }^{5}$, multimedia ${ }^{6}$, for instance interactive maps, as well as stakeholder engagement events with affected municipalities, in France communication the radon issues targets a broader public, mainly in schools. An educational guide was written to explain radon risks for schools; in addition the students were given the opportunity to do their own measurements. This approach is a way to create an 'empowerment' of the citizen and helps to increase the two way communication.

In the medical field, the Health Department of the Belgian Government in collaboration with FANC launched a reoccurring campaign in 2013 to increase the lay public's awareness of medical imaging techniques and risks from exposure to ionising radiation ${ }^{7}$. Hospitals put brochures at the waiting rooms in hospitals in an attempt to inform patients about risks and benefits related to screening and treatments using ionising radiation. Also in France, Public Awareness Campaigns have been launched by Patient Associations and other partners (e.g. IRSN) on radiography and computerised tomography and the potential risks involved ${ }^{8}$.

An active communicator related to the different applications of nuclear technology in both countries is the nuclear industry, which is linked to the international organisation Nuclear

\footnotetext{
${ }^{5}$ www.fanc.fgov.be/nl/page/publicaties/853.aspx;

${ }^{6}$ www.fanc.fgov.be/nl/page/646.aspx \#P 1903

${ }^{7}$ www.zuinigmetstraling.be

${ }^{8}$ www.irsn.fr/FR/connaissances/Sante/applications-medicales/radiologie-scanner/Pages/sommaire.aspx
} 
Forum. The Forum launches regularly campaigns using extensive internet, TV and printed press advertising. Such campaigns revolve around a series of key questions aimed at stimulating citizens to think about nuclear technology.

\section{Potential influencing factors}

\subsection{Socio-demographic characteristics of the respondent}

Gender, age, education and specific knowledge or experiences with the issue were shown in previous studies to influence the self-assessed familiarity with the issue and the willingness to spend time to get information. For instance, respondents with higher levels of education and personal experience are more likely to feel well informed on safety issues concerning nuclear power plants (Eurobarometer 324 2010) and are more willing to spend time to get informed about installations with risks (Turcanu and Perko 2011). Differences among generations were observed in terms of actively looking for information about radioactive waste disposals in a municipality having agreed to host a spent fuel waste repository and neighbouring municipalities (Kari et al 2010), younger generations being less proactive. In the same study, differences in satisfaction with the quality of information were also found among various education levels, but without a consistent pattern with increasing education level. Men were found to be more satisfied than women with the quantity and quality of information provided by the waste management organisation, the nuclear industry and the regulatory authority (Kari et al 2010).

Perko et al (2013) found that people with higher knowledge are more able to pay attention to information concerning emergency preparedness, as well as comprehend, remember and recall it. However, knowledge did not influence the level of agreement with information concerning the management of a radiological emergency (Perko et al 2014).

A study on patient satisfaction with information (Verkissen et al 2014) showed that lower domain-specific literacy (subjective health literacy) was associated with less perceived information and lower satisfaction with information; in the same study, lower education was however associated with more perceived information provision. This implies that the familiarity with the domain might be linked to the satisfaction with domain-specific information. Based on the literature results we formulated the following hypotheses:

$H_{1}$ : Higher specific knowledge leads to higher satisfaction with information about ionising radiation.

$\mathrm{H}_{2}$ : The education level is not a significant predictor for the satisfaction information.

\subsection{Risk perception}

Satisfaction with the information on energy options was shown to be influenced by perceived risks and benefits (Eurobarometer 324 2010), and the general attitude towards nuclear energy (Nuclear Forum 2013 www.nucleairforum.be/sites/default/files/peiling_kernenergie_2013_ nl_final_2_0.pdf).

Risk perception was also shown to be negatively correlated to the satisfaction with public meetings for risk communication in the case of landfill project (McComas 2003). People who perceived risks to be higher were less satisfied with the public meetings. However, later research by Besley et al (2012) did not find risk perception to be a significant predictor of satisfaction with public meetings on health related information. The question is whether risk perception is an influential factor for the satisfaction with information. Based on these findings we formulate the following hypothesis: 
(H3): People who perceive the risks of ionising radiation to be high are less satisfied with the public information provided by the different communicators.

\subsection{Trust in the information sources}

Trust is a multi-level construct reflecting the 'generalized judgment whether and to what degree the perceived performance of an organisation matches the (...) shared expectations' (Renn 2008, p 223) of stakeholders, and is a major objective in risk communication (Renn 2008, p 222). Trust in the information sources inherently influences satisfaction with information: 'if trust is lacking no form or process of communication will be satisfactory' (Slovic 1993 quoting Fessenden-Raden et al 1987).

For instance, the effect of credibility of government agencies was found to be a significant predictor of satisfaction with public meetings they organised on risk communication for a landfill site (McComas 2003). People who perceived government agencies to be more credible were more satisfied with the public meetings. In a later study by Besley et al (2013), the credibility of a health agency was not related to the satisfaction with public meetings.

Perceived competence and truthfulness are two important trust dimensions, alongside objectivity, fairness, consistency, faith and empathy (Renn and Levine 1991, Covello 1992). Taking these two dimensions together, independent scientists and family doctors are generally perceived as the most trusted sources of information among the actors in the nuclear field, whereas the politicians and the journalists are among the least trusted sources of information (Eurobarometer 324 2010, Turcanu et al 2011, El Jammal et al 2013, Turcanu and Perko 2014a). Previous studies on public perception in Belgium and France also show that the nuclear industry scores relatively high on competence, but lacks in truthfulness, whereas the government is perceived as underperforming on both dimensions. In addition, trustworthiness is generally perceived as lower than the technical competence for most of the actors in the nuclear field, with the exception of family doctors, environmental organisations and journalists in Belgium (Turcanu et al 2011, Turcanu and Perko 2014a) and the consumers' associations and the journalists in France (El Jammal et al 2013).

Peters et al (1997) showed that three determinants: knowledge and expertise, honesty and openness, and concern and care are the most significant predictors of trust and credibility in environmental risk communication. However, their study also showed that these predictors played different roles in the context of various communicators, the key to improving perceptions of trust and credibility being defying the specific negative stereotype (e.g. that citizens groups have low knowledge of public health and safety issues, or that the industry lacks concern).

Drawing on this, we formulate the following, final hypothesis:

(H4): Perceived trustworthiness and competence will be the most influential predictors for the satisfaction with information and their role will differ depending on the specific actor considered.

\section{Method}

\subsection{Data collection and sampling}

The data used for Belgium originate from a large scale opinion survey $(N=1002)$, carried out between the 15th of August and the 3rd of September 2013. The sample of people interviewed is representative of the Belgian adult (18+) population with respect to province, region, and level of urbanisation, gender, age and professionally active status. The field work for data 
Table 1. Characteristics of the Belgian and French samples.

\begin{tabular}{lll}
\hline & $\begin{array}{l}\text { Belgian sample } \\
(N=1002)\end{array}$ & $\begin{array}{l}\text { French sample } \\
(N=966)\end{array}$ \\
\hline Gender & & \\
Male & $50.6 \%$ & $48 \%$ \\
$\quad$ Female & $49.4 \%$ & $52 \%$ \\
\hline Education & & \\
$\quad$ Lower (incl. no diploma) & $27 \%$ & $38 \%$ \\
Secondary & $43 \%$ & $20 \%$ \\
Higher & $30 \%$ & $42 \%$ \\
\hline Age (years) & & \\
18-24 & $12 \%$ & $9 \%$ \\
$25-34$ & $12 \%$ & $12 \%$ \\
$35-49$ & $27 \%$ & $27 \%$ \\
$50-64$ & $30 \%$ & $28 \%$ \\
$\geqslant 65$ & $20 \%$ & $24 \%$ \\
\hline
\end{tabular}

collection was performed by a professional market research company (IPSOS) using Computer Assisted Personal Interviews (CAPI). The CAPI method entails personal interviews taken by a professional interviewer at the home of the respondent, with answers directly recoded and stored on computer hard disk. The interviews were carried out in Dutch or in French language, according to the preference of the interviewee.

For the French sample the interview method used was CATI (Computer-Assisted Telephone Interviews).

The data were collected from the 25th till the 28th of April 2014. BVA, a French polling organisation, conducted the questionnaire-based phone survey on a representative sample of 966 French citizens aged 18 years old and over as part of an omnibus survey, i.e. a survey conducted for several companies. In order to ensure that the population was representative, a quota sampling method was used to divide respondents according to gender, age, profession of the head of household, region and habitat. Education was not among the quota variables in the two countries, but the representation of the three education groups was respected as much as possible. In the Belgian sample the distribution of education levels was $26.9 \%, 43.5 \%$ and $29.6 \%$ for lower, secondary and higher education (compared to $29.1 \%, 40.5 \%, 30.4 \%$ in the Belgian population, Turcanu and Perko 2014a) and in France this was 38\%, 20\%, 42\% (compared to $53.4 \%, 18 \%$ and $28.6 \%$ in France, IRSN 2015). In the French sample, the education level was thus higher than in general population in France. To allow comparison, the questions asked were largely the same as those used in the questionnaire in Belgium. However some questions were adjusted, but only for compatibility reasons with a telephone survey.

The characteristics of the two samples are summarised in table 1. It can be seen that the two population samples are comparable with respect to gender distribution and age, but the level of education is higher in the French sample.

\subsection{Measurements for dependent and independent variables}

The dependent variable satisfaction with information was measured with the question 'In general, are you satisfied with the public information related to ionising radiation provided by the following communicators'. The 5-point answering scale used for this question ranged from 'definitely yes' to 'definitely no'. Among the actors in focus were the nuclear safety 
Table 2. Knowledge about ionising radiation in Belgium and France.

\begin{tabular}{|c|c|c|c|c|}
\hline \multirow[b]{2}{*}{ Knowledge question } & \multicolumn{2}{|c|}{$\%$ correct } & \multicolumn{2}{|c|}{$\%$ incorrect } \\
\hline & $\mathrm{BE}$ & $\mathrm{FR}^{\mathrm{a}}$ & $\mathrm{BE}$ & $\mathrm{FR}^{\mathrm{a}}$ \\
\hline $\begin{array}{l}\text { Natural Radioactivity is never dangerous because we are } \\
\text { used and adapted to it (Correct: No) }\end{array}$ & $51 \%$ & $54 \%$ & $35 \%$ & $45 \%$ \\
\hline $\begin{array}{l}\text { With time, every radioactive substance becomes more and } \\
\text { more radioactive (Correct: No) }\end{array}$ & $47 \%$ & $58 \%$ & $29 \%$ & $37 \%$ \\
\hline The human body is naturally radioactive (Correct: Yes) & $37 \%$ & $52 \%$ & $40 \%$ & $42 \%$ \\
\hline $\begin{array}{l}\text { Vegetables grown near a nuclear power plant are not good } \\
\text { for consumption because of radioactivity (Correct: No) }\end{array}$ & $34 \%$ & $39 \%$ & $58 \%$ & $60 \%$ \\
\hline
\end{tabular}

${ }^{\text {a }}$ Slightly higher education level in the French sample compared to the general population in France.

authorities, the nuclear industry, the medical personnel in hospitals and the mass media (Turcanu and Perko 2014b).

Risk perception was measured with the question 'How do you perceive the potential risk to your health from each of the following sources within the next 20 years', with six answering categories ranging from 'no risk at all', through to 'very low risk' up to 'very high risk'. Five radiological risks were considered: a nuclear accident, radioactive waste, medical x-rays, residues of radioactivity in food and natural radiation.

Confidence in authorities for the management of the same radiological risks was measured with the question 'How much confidence you have in the authorities to protect the population against risks from each of the following...?', with answers ranging from 'very low' to 'very high' (5-point Likert scale).

In the Belgian sample we also measured the perceived trustworthiness and competence of the different actors: 'How much do you agree or disagree that the following actor is telling the truth (respectively, is technically competent) concerning the risks and benefits of nuclear technologies'. These variables were measured only for the respondents that knew the respective actors. Answers were coded on a 5-point Likert scale ranging from 'strongly disagree' to 'strongly agree'.

For all variables mentioned above the respondents had the possibility to answer 'I don't know', which was later on recoded as missing value.

The specific knowledge of the respondent related to ionising radiation (see table 2) was measured as actual knowledge rather than perceived knowledge or familiarity with the domain. For this purpose, four questions were used, with answering categories 'agree', 'disagree' and 'I don't know'. For instance the respondents were asked whether they agreed or not that 'the human body is naturally radioactive'. In order to use knowledge as a potential predictor for the satisfaction with information, an index was created by counting the number of correct answers given on four knowledge questions.

\subsection{Data analysis}

The dependent and independent variables were generally assumed to be measured at an interval level.

Two variables, namely perception of radiological risks and confidence in authorities were measured as multiple-item constructs and used in further analysis as factor scores. For these variables, factor analysis was used to verify that the items used to construct these variables belong to a 1D construct (see appendix) using Principal Axis Factoring and direct oblimin rotation. In addition, reliability tests were conducted using Cronbach's alpha coefficient, 


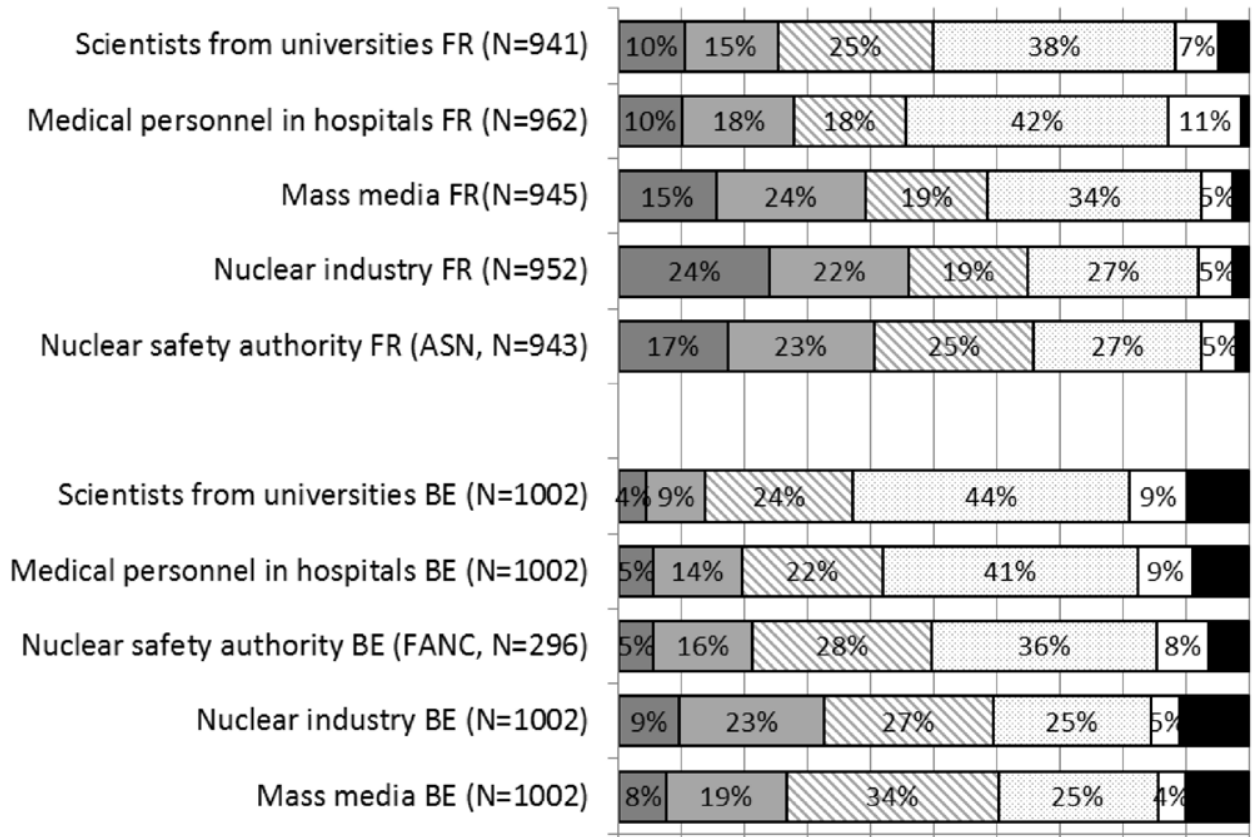

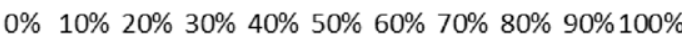

$\square$ Rather unsatisfied

$\square$ Very unsatisfied

$\square$ Neither satisfied, nor unsatisfied $\square$ Rather satisfied

$\square$ Very satisfied

Don't know/NA

Figure 1. Satisfaction with public information on ionising radiation provided by different communicators.

a value higher than 0.7 indicating a reliable scale, which is the case for both aforementioned constructs.

The strength of associations between the dependent and independent variables were determined on the basis of Spearman's rho correlation coefficient $\left(r_{\mathrm{S}}\right)$, while the potential explanatory power of the independent variables was investigated using linear regression.

The statistical package SPSS was used for all statistical analysis.

\section{Results}

In Belgium, as illustrated in figure 1, the respondents (27\%) were least satisfied with the information provided by mass media and the nuclear industry (less than one in three is satisfied or very satisfied). In general, they are most satisfied with the information provided by scientists from universities (53\% satisfied or very satisfied) and medical personnel (50\%). For the nuclear safety authority, the level of satisfaction is somewhat lower (about $45 \%$ are satisfied or very satisfied).

In France even more so than in Belgium, the respondents were least satisfied with the information by the nuclear industry. The French respondents consider that among the different communicators most satisfactory in terms of public information about ionising radiation are the medical personnel in hospitals $(53 \%)$ and university scientists $(45 \%)$. 


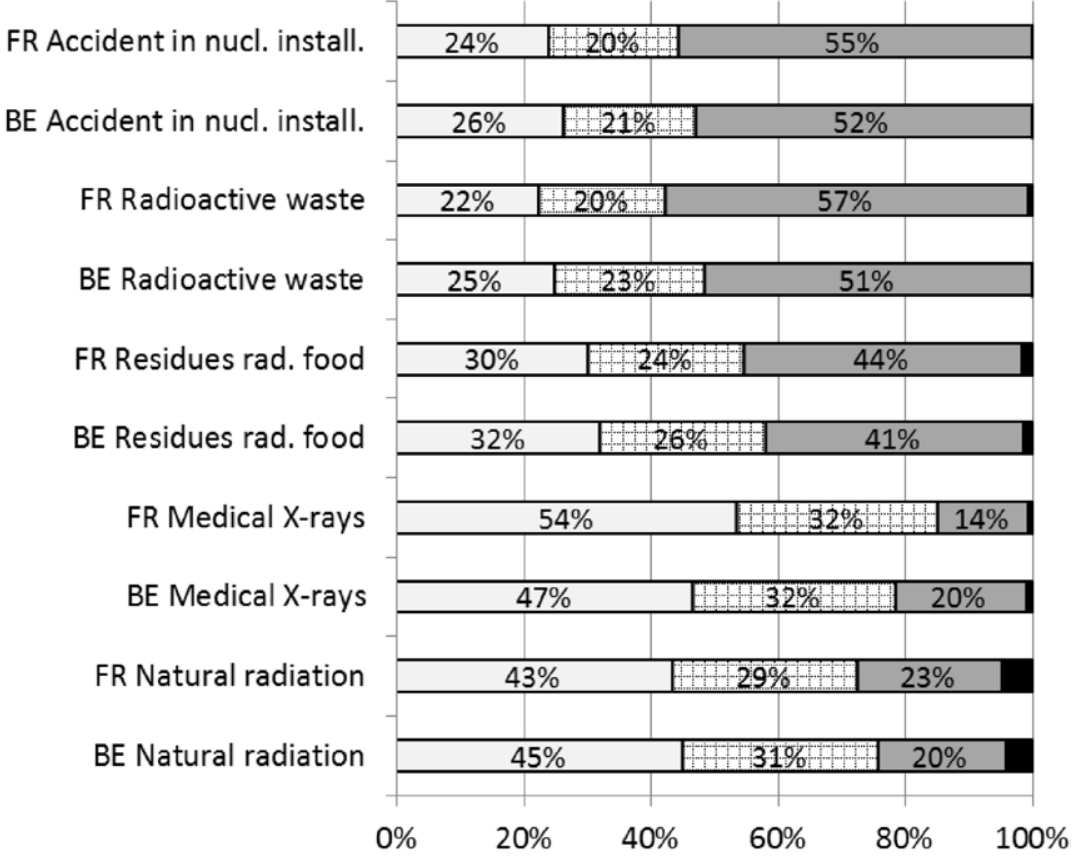

\section{$\square$ Low, very low or no risk $\square$ Medium risk $\square$ High or very risk $\square$ Don't know}

Figure 2. Risk perception for various radiological risks.

It should be noted that nuclear actors are better known among the French respondents than among the Belgian respondents. For instance, only $30 \%$ of the Belgian respondents knew the nuclear safety authority, whereas in France this was the case for more than $95 \%$ of the respondents.

The results on the questions probing the respondents' knowledge of ionising radiation (table 2) showed that some of the basic concepts are known to about half of the population in both countries (e.g. related to radioactive decay). However, misunderstandings are also present. For instance, the majority of the respondents in both countries think that vegetables growing close to a nuclear power plant are not good for consumption due to radioactivity.

Risk perception of the different radiation related risks was very similar in both Belgium and France, as illustrated in figure 2. For medical x-rays, risk perception is slightly lower in France than in Belgium.

Results showed that the respondents from both countries consider that industry-related risks are high. They are particularly concerned about radioactive waste and accidents in nuclear installations. Opposite to this, medical x-rays and natural radiation are perceived as posing low or very low health risk. This can be attributed to these risks being perceived as voluntary, controllable and natural (in the case of radon), as opposed to accidents in nuclear installations, for instance, that are perceived as involuntary risks, with catastrophic potential and tampering with nature (Slovic 1987, Sjöberg 2000).

For each population sample a separate factor analysis (Principle Axis Factoring) was conducted for the risk perception items. Both the FA on the French sample and the Belgian sample result in a single factor solution, indicating that risk perception is unidimensional in both countries. Factor loadings are summarised in appendix. 


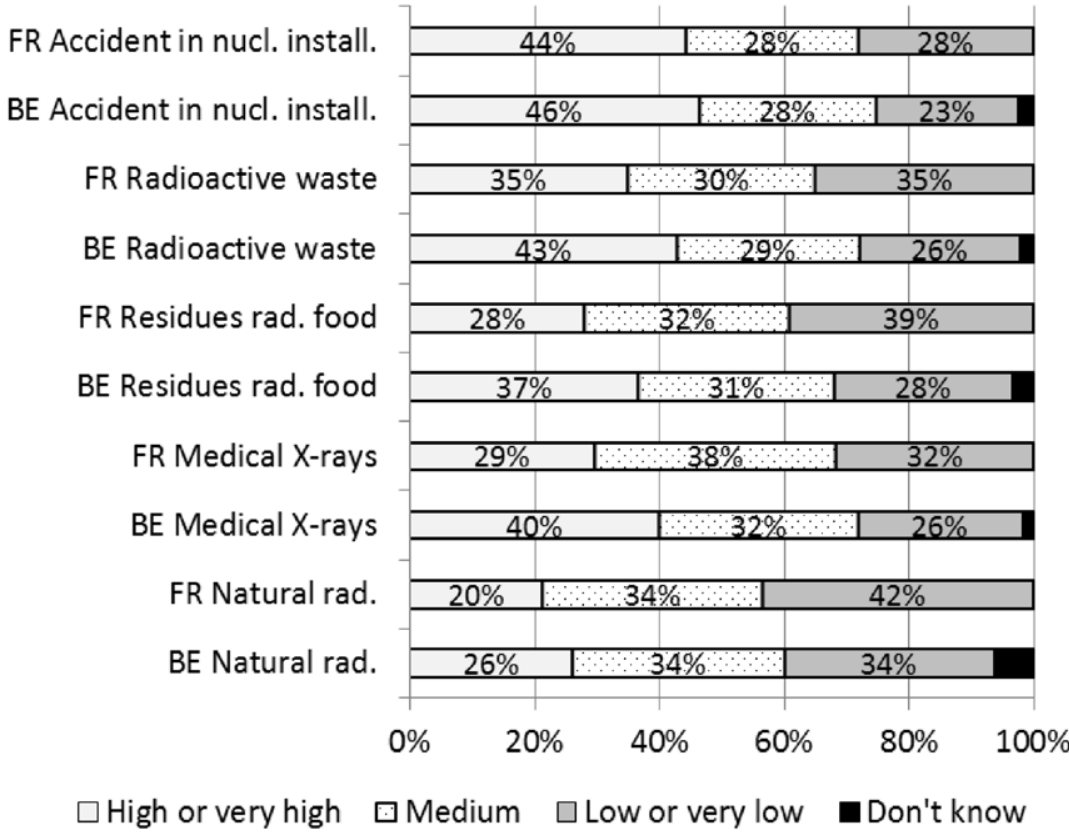

Figure 3. Confidence in authorities for various radiological risks.

The level of confidence in authorities was generally higher among the Belgian respondents as compared to the French respondents (figure 3). Interestingly, for both countries the highest levels of confidence in authorities for the actions taken in order to mitigate risks were expressed for accidents in nuclear installations and radioactive waste, which were the items perceived as posing the highest risks. The nuclear risks that people consider the highest are therefore those for which they have the greatest confidence in the protective measures implemented by the authorities. Conversely, they have little confidence in measures taken by the authorities regarding natural radiation.

Similar to the risk perception items, factor analysis applied on each population sample (BE and FR) separately resulted in one factor containing all confidence items. Factor loadings are summarised in appendix.

In order to identify potential predictors for satisfaction with the information, the correlations between the dependent and independent variables were calculated (tables 3 and 4). Results highlight that the correlation between the satisfaction with the information provided by different communicators and the specific knowledge of the respondent was either not statistically significant or very low. Knowledge seemed to influence to a limited extent $\left(r_{\mathrm{S}}=0.141\right)$ satisfaction with the information provided by the nuclear safety authorities in Belgium, a higher level of knowledge being associated, to a very limited extent, with a higher satisfaction with information. People with higher knowledge could be less satisfied with the information provided by mass media (in Belgium, $r_{\mathrm{S}}=-0.08$ ) or the medical personnel (in France, $\left.r_{\mathrm{S}}=-0.078\right)$, but the correlation values show that these associations are extremely weak. Therefore hypothesis $H_{1}$ can be accepted only for the satisfaction with the information provided by nuclear safety authorities in Belgium. Due to its low correlation with satisfaction with information, knowledge was not taken into consideration in the further analysis.

The education level of the respondent was not significantly correlated to satisfaction with information provided by any of the communicators in either of the two countries. The exception was 


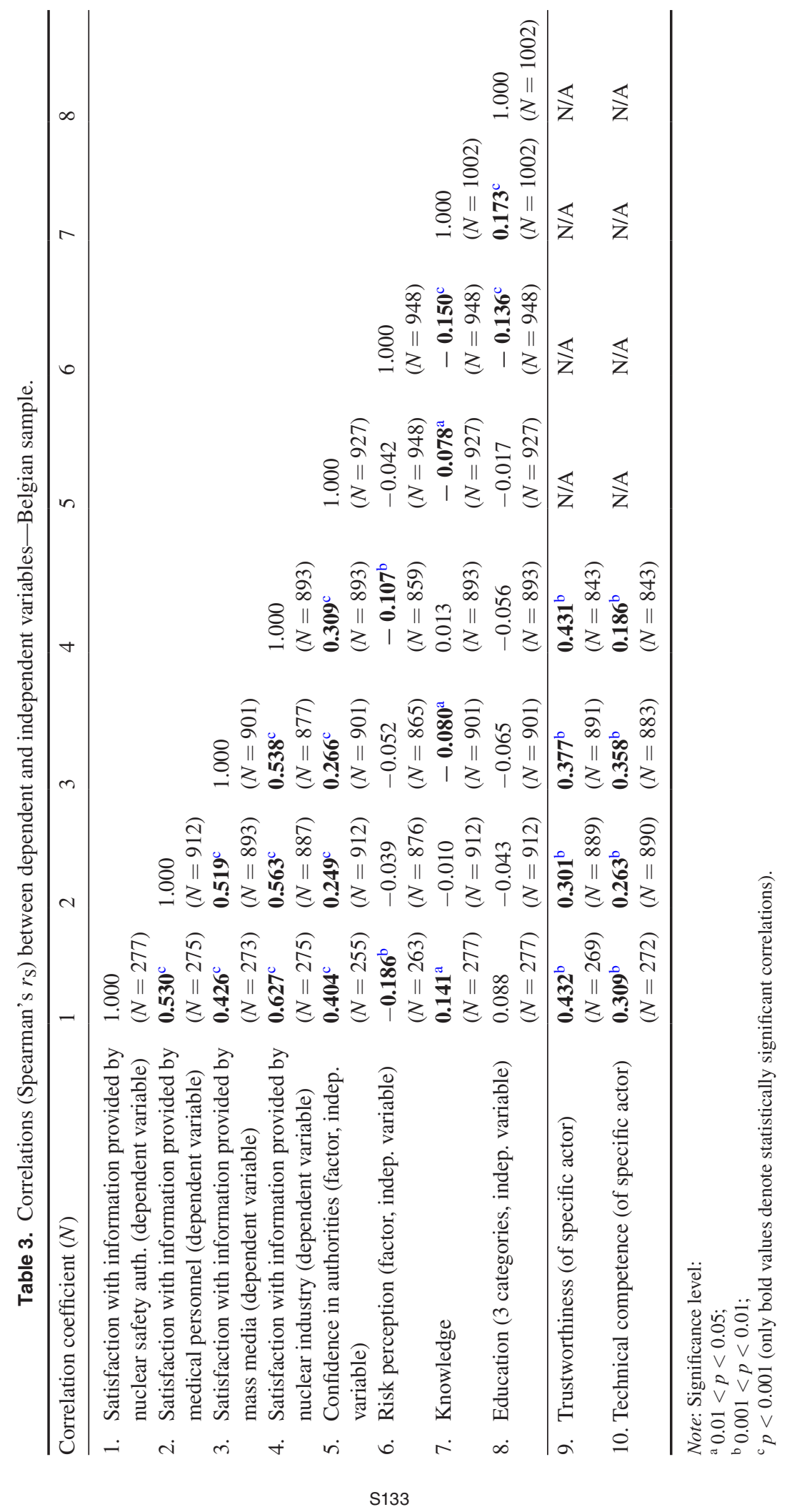




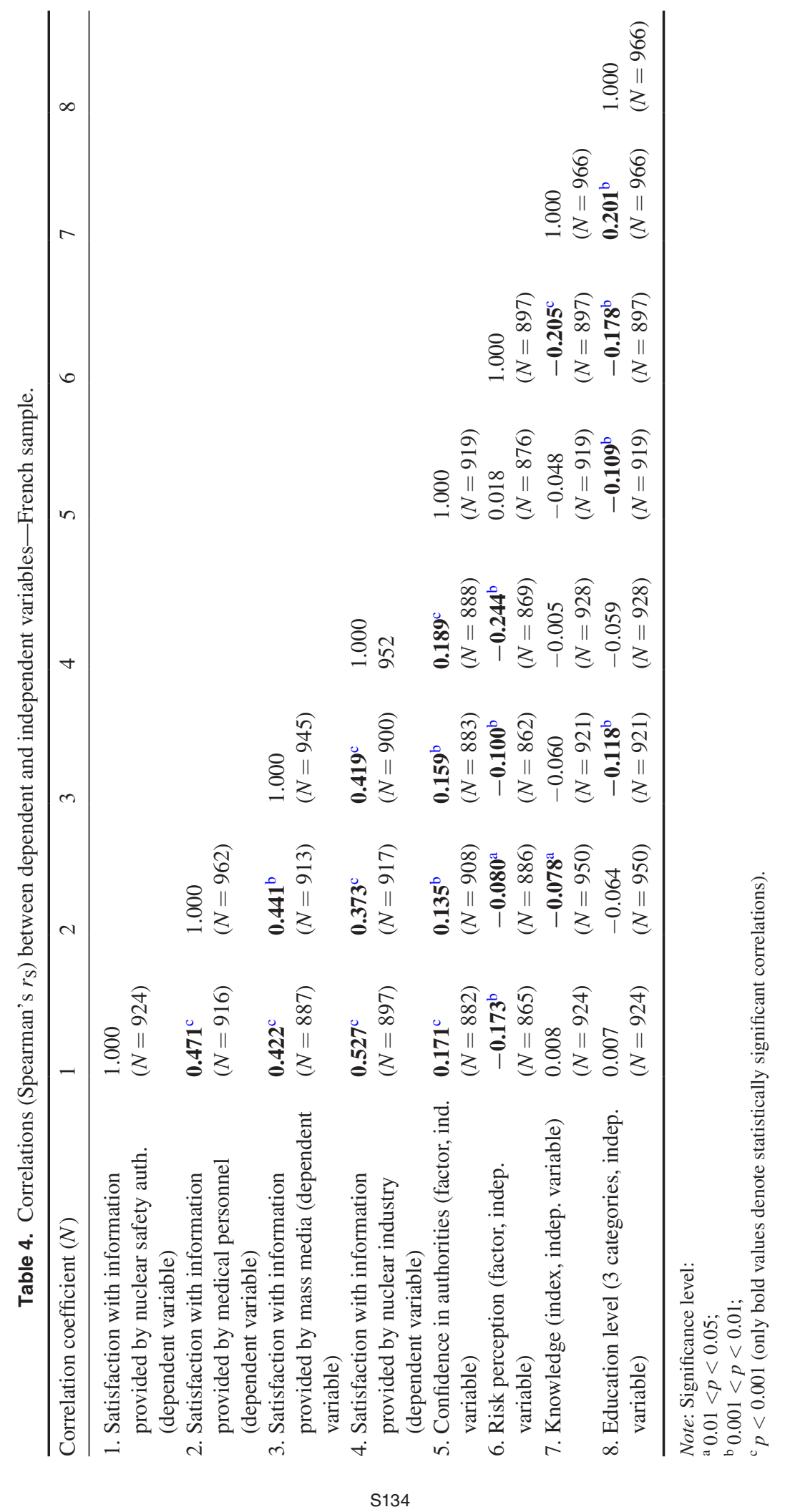


satisfaction with the information provided by the mass media in France $\left(r_{\mathrm{S}}=-0.118\right)$, where a higher education was associated with lower satisfaction with information. Therefore, the second hypothesis $\left(\mathrm{H}_{2}\right)$ is in general confirmed and the education level was not included in further analysis.

However, it should be noticed that in both countries people with higher knowledge and/ or higher education had a somewhat lower risk perception of ionising radiation risks. This implies for instance that risk perception could be higher in the general population in France than in the sample analysed in this study.

Risk perception was significantly correlated with satisfaction with information provided by some communicators. People with lower risk perception were more satisfied with public information about ionising radiation provided by nuclear safety authorities and nuclear industry (both countries) and medical personnel and media (only France).

Confidence in authorities was positively related to satisfaction with information in all contexts: higher confidence is associated with higher satisfaction with information in both countries and for all communicators. It can be noted that perception of ionising radiation risks was not correlated with the confidence in authorities for the actions taken to manage these risks.

As illustrated in table 3 , the correlation between the trustworthiness of Belgian communicators and their perceived technical competence, on the one hand, and the satisfaction with public information they provide, on the other hand, was statistically significant for all communicators. In addition, trustworthiness was positively correlated with technical competence; the highest value for this correlation was noted for the media $\left(r_{\mathrm{S}}=0.566\right)$ and the lowest for the nuclear industry $\left(r_{\mathrm{S}}=0.299\right)$.

Next, linear regression models were constructed to assess the predictive power of risk perception, confidence in authorities (both samples) and trustworthiness and competence of the four actors (only Belgian sample) on the satisfaction with information. The results are presented in tables 5 (Belgium) and table 6 (France).

The third hypothesis, that higher risk perception is associated with lower satisfaction with information is confirmed in both countries (models $M_{1}$ and $M_{9}$ ) only for the nuclear industry. For the nuclear safety authorities $\left(M_{10}\right)$, the medical personnel $\left(M_{11}\right)$ and the media (model $M_{12}$ ) the influence of risk perception was confirmed only in France.

Hypothesis $H_{4}$, that confidence in authorities for the actions taken to protect the population from risks due to ionising radiation is positively related to satisfaction with information was confirmed for all communicators in both countries.

Models $M_{1}, M_{3}, M_{5}, M_{7}$ and $M_{10}-M_{12}$ indicate that the explanatory power of risk perception and confidence in authorities is rather low in both countries.

The extended models for the Belgian sample $\left(M_{2}, M_{4}, M_{4}, M_{8}\right)$ tested the explanatory role of trustworthiness ('telling the truth') and technical competence of communicators as regards the risks and benefits of nuclear technologies. Results show that the explanatory value of the models increased for all four communicators. The higher the perceived trustworthiness of communicators, the higher is satisfaction with information provided by the four communicators. Trustworthiness of the nuclear industry was the most influential factor for the satisfaction with information provided by the nuclear industry. However, in the case of the media, the perceived technical competence of journalists was the most influential factor for satisfaction with information. For the nuclear safety authorities and the medical personnel, trustworthiness was as important as confidence in authorities.

\section{Discussion}

Broader societal involvement in nuclear decision-making and two-way communication is increasingly recommended at national and supra-national levels for all aspects of the nuclear 


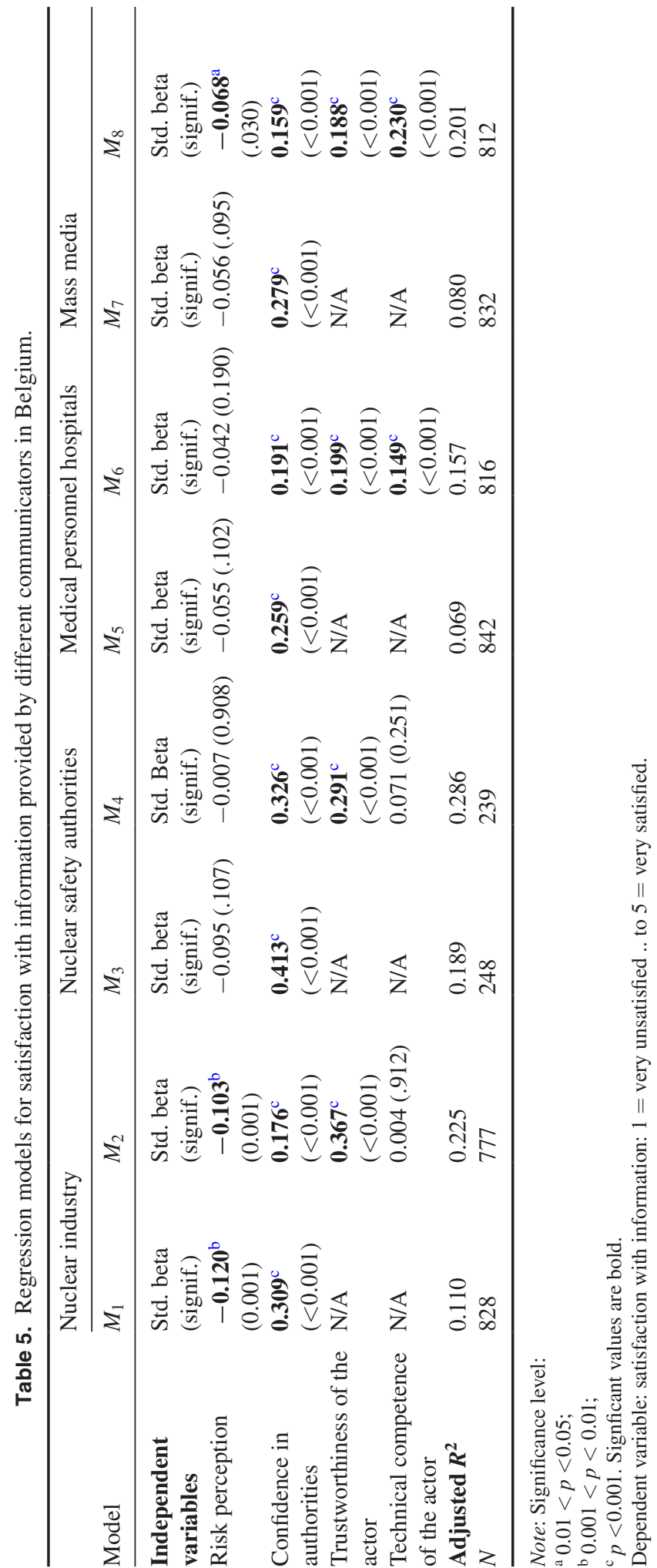


Table 6. Regression models for satisfaction with information provided by different communicators in France.

\begin{tabular}{|c|c|c|c|c|}
\hline & Nuclear industry & $\begin{array}{l}\text { Nuclear safety } \\
\text { authorities }\end{array}$ & $\begin{array}{l}\text { Medical personal } \\
\text { hospitals }\end{array}$ & Mass media \\
\hline Model & $M_{9}$ & $M_{10}$ & $M_{11}$ & $M_{12}$ \\
\hline $\begin{array}{l}\text { Independent } \\
\text { variables }\end{array}$ & $\begin{array}{l}\text { Std. beta } \\
\text { (signif.) }\end{array}$ & $\begin{array}{l}\text { Std. beta } \\
\text { (signif.) }\end{array}$ & $\begin{array}{l}\text { Std. beta } \\
\text { (signif.) }\end{array}$ & $\begin{array}{l}\text { Std. beta } \\
\text { (signif.) }\end{array}$ \\
\hline Risk perception & $\begin{array}{l}-\mathbf{0 . 2 4 1} 1^{\mathrm{c}} \\
(<0.001)\end{array}$ & $\begin{array}{l}-\mathbf{0 . 1 8 2}^{\mathrm{c}} \\
(<0.001)\end{array}$ & $\begin{array}{l}-0.067^{a} \\
(0.049)\end{array}$ & $\begin{array}{l}-\mathbf{0 . 0 9 3}^{\mathrm{b}} \\
(.006)\end{array}$ \\
\hline $\begin{array}{l}\text { Confidence in } \\
\text { authorities }\end{array}$ & $\begin{array}{l}\mathbf{0 . 1 9 4 ^ { c }} \\
(<0.001)\end{array}$ & $\begin{array}{l}\mathbf{0 . 1 8 8}^{\mathrm{c}} \\
(<0.001)\end{array}$ & $\begin{array}{l}\mathbf{0 . 1 1 6}^{\mathrm{b}} \\
(0.001)\end{array}$ & $\begin{array}{l}\mathbf{0 . 1 6 7}^{\mathrm{b}} \\
(<0.001)\end{array}$ \\
\hline $\begin{array}{l}\text { Trustworthiness of the } \\
\text { actor }\end{array}$ & NA & NA & NA & NA \\
\hline $\begin{array}{l}\text { Technical competence } \\
\text { of the actor }\end{array}$ & NA & NA & NA & NA \\
\hline Adjusted $R^{2}$ & 0.095 & 0.067 & 0.016 & 0.035 \\
\hline$N$ & 850 & 845 & 866 & 844 \\
\hline
\end{tabular}

Note: Significance level:

a $0.01<p<0.05$

${ }^{\mathrm{b}} 0.001<p<0.01$

${ }^{\mathrm{c}} p<0.001$. Significant values are bold.

Dependent variable: satisfaction with information: $1=$ very unsatisfied .. to $5=$ very satisfied.

fuel cycle. This has contributed to acknowledging the need for a change of paradigm, from one-way communication focusing on enhancing lay public knowledge, to two-way communication enabling informed decision-making. Moreover, active participation in the communication process instead of passive reception of information increases the communication effects. Research reported elsewhere showed that among the members of a local community in Belgium where a partnership for low and intermediate level radioactive waste disposal was established, and who act as active communicators, $70 \%$ are satisfied or very satisfied with information about radioactive waste disposal (Turcanu and Perko 2014c). Opposite to this, only $49 \%$ among members of the general public in Belgium (passive receivers of information) who know the agency for radioactive waste management are satisfied or very satisfied with the information they provide (Turcanu and Perko 2014a).

Notwithstanding this, the present study investigated satisfaction with the information about ionising radiation provided by different actors, at different levels of communication involvement, from information provision (e.g. about iodine tablets) to stakeholder engagement (e.g. on radon issues). It focuses on satisfaction with the information provided by some of the most active nuclear communicators: the nuclear safety authorities, the industry, the medical personnel and the media. In addition, the study analysed the explanatory power of latent variables of interest in risk research. The detailed analysis of the frequency and quality of information, including a balanced content showing both risks and benefits, were beyond the scope of this study.

The results of the study show that in both Belgium and France there is still much room for improvement in what concerns communication about ionising radiation. People in both countries are least satisfied with the information provided by the nuclear industry and mass media and more satisfied with the information provided by scientists from universities and medical personnel. Satisfaction with information provided by university scientists is somewhat lower in France than in Belgium. Only 45\% (out of 941) were very satisfied or rather satisfied with the information provided by scientists in France, although the French CREDOC barometer 
(opinion poll over the same period 2013) showed that a large majority of lay people (73\%) considered that scientists have a good knowledge of the impact on health further to environmental pollution (Daudey 2015).

Specific knowledge about ionising radiation, education, perception of radiological risks, and confidence in authorities with respect to managing radiological risks (Belgium and France), as well as trustworthiness and competence of nuclear communicators (only Belgium) were investigated as potential predictors for the satisfaction with public information provided by four communicators.

Knowledge was somewhat higher in the French, compared to the Belgian sample. The percentage of correct answers to the knowledge questions was larger among the French respondents, presumably due to the higher education level being higher in the sample than in the general population in France. However, the percentage of incorrect answers was also larger in the French sample. Higher specific knowledge has been previously linked to increased reception of information, but it has a limited effect on the agreement with information (Perko et al 2014). In line with this, our study showed that knowledge had a minor or no influence on the satisfaction with public information provided by nuclear communicators.

Similar models applied in Belgium and France with risk perception and confidence in authorities as independent variables showed that risk perception and confidence in authorities can explain to a very limited extent the satisfaction with public information provided by different communicators (less than $10 \%$ of the variance in the data explained). An exception to this was noted for the nuclear safety authorities in Belgium, where confidence in the risk management by authorities was somewhat more influential $\left(R^{2}=0.19\right)$. In France, risk perception seemed to play a somewhat more important role than confidence in authorities, but the explanatory power of the regression models was very limited. In both Belgium and France, lower risk perception was linked to higher satisfaction with the information provided by the nuclear industry; in fact in France risk perception was even more important than confidence in authorities for this communicator. In Belgium, risk perception was either not statistically significant as a predictor, or much less influential than confidence in authorities.

The results also show that there are differences between Belgium and France as regards the explanatory value of risk perception and confidence in authorities. This indicates that country differences (including also the nuclear safety policy or education system) have to be taken into account in communication about radiological risks.

The models applied for the Belgian sample, in which trustworthiness and competence were added to the regression models, led to improved models with higher explanatory power. As expected from the literature (Peters et al 1997), in the case of the nuclear industry, trustworthiness was the most important predictor for satisfaction with information. Alongside the proven influence of risk perception, this shows that transparency and balanced risk communication are essential for the nuclear industry.

For the nuclear safety authorities, confidence in the governance of radiological risks by the authorities and trustworthiness were revealed as the most influential predictors, the full model accounting for almost $30 \%$ of the variance in the data. A higher confidence in the measures taken by authorities to protect the population against radiological risks leads to higher satisfaction with the information provided by all communicators, in particular the industry and the medical field. Such measures could include a demand for continuous improvement of their communication with the general public.

In what concerns communication by the media, the perceived technical competence was revealed as even more important than trustworthiness and confidence in authorities. This resonates with the need for specialised journalism pointed out in the dialogues with journalists carried out in the framework of the EAGLE project (Mays et al 2016). 
For the medical personnel, confidence in authorities, trustworthiness and technical competence concerning the risks and benefits of nuclear technologies play an equally important role as regards people's satisfaction with information about ionising radiation.

\section{Limitations of the study}

Certain limitations of this study can be mentioned. The interviewing method was different: CAPI in Belgium and CATI in French, which may cause differences in data quality since in face-to-face interviewers are physically present which gives more opportunity to clarify difficult questions and improve the accuracy of the data (Sloan et al 2010). Telephone respondents are also reported to be more likely to satisfice, less engaged and more likely to present themselves in socially desirable ways than face-to-face respondents (Holbrook et al 2003). In addition, data was collected at few months' difference in Belgium and France. While no major nuclear/radiological events occurred in this time period, public discourse, including media, might have led to some differences in attention to topics related to ionising radiation.

The samples from the Belgian and French populations differed also as regards the level of education. This might have influenced the slightly higher level of knowledge among the French respondents and the slightly lower risk perception. However, education has been shown in the study to have no effect on the satisfaction with information.

Finally, a limitation of the study is that it focused on satisfaction with information provided by different sources of information. Future studies should therefore address communication in connection to stakeholder involvement.

\section{Conclusions}

Public participation in risk management and the frequency of information provision, channels used and quality of information are known to contribute to higher satisfaction with information. This study stressed the importance of trust in communicators on the satisfaction with information they provide to the general public. The results of the study show that in both Belgium and France communication about ionising radiation should be improved, especially in what concerns communication by the nuclear industry and the mass media. In particular, the importance of their perceived technical competence shows the need for journalists specialised in reporting about ionising radiation topics. The study also confirmed that country characteristics should be taken into account in communicating about ionising radiation.

The study also accentuates the role of authorities in promoting open and transparent communication by the nuclear actors. The limited influence of risk perception, knowledge and the stronger influence of confidence in authorities, trustworthiness and perceived competence on the satisfaction with information plead for a responsible relation with stakeholders in order to enable citizens to make informed decisions related to ionising radiation risks.

Further research should investigate communication from the perspective of opportunities for social dialogue and satisfaction with stakeholder engagement processes linked to the different aspects of nuclear technology and applications of ionising radiation.

\section{Acknowledgments}

This study received funding from the European Union's Seventh Framework Programme for research, technological development and demonstration under grant agreement no 604521 . Data collection in Belgium was partly funded through the R\&D collaboration agreement between SCK•CEN and GDF-SUEZ (Project 17). 


\section{Appendix}

Table A1. Factor analysis for risk perception items.

\begin{tabular}{lll}
\hline $\begin{array}{l}\text { Potential risk for your own health } \\
\text { within 20 years from... }\end{array}$ & Belgium & France \\
\cline { 2 - 3 } & Factor loadings & Factor loadings \\
\hline Radioactive waste & 0.823 & 0.823 \\
Nuclear accident & 0.769 & 0.786 \\
Natural radiation & 0.717 & 0.624 \\
Medical x-rays & 0.593 & 0.501 \\
Radioactive residues in food & 0.842 & 0.743 \\
\hline \% Variance explained & $65 \%$ & $59 \%$ \\
\hline Cronbach alpha ${ }^{\text {a }}(N)$ & $0.864(N=948)$ & $0.820(N=966)$ \\
\hline
\end{tabular}

${ }^{\text {a }}$ A value higher than 0.7 indicates a reliable scale.

Table A2. Factor analysis for confidence in authorities.

\begin{tabular}{lll}
\hline $\begin{array}{l}\text { Confidence in government to } \\
\text { protect the population against the } \\
\text { risks of: }\end{array}$ & Belgium & France \\
\cline { 2 - 3 } & Factor loadings & Factor loadings \\
\hline Radioactive waste & 0.852 & 0.782 \\
Nuclear accident & 0.816 & 0.703 \\
Natural radiation & 0.658 & 0.630 \\
Medical x-rays & 0.705 & 0.465 \\
Radioactive residues in food & 0.835 & 0.739 \\
\hline \% Variance explained & $68 \%$ & $55 \%$ \\
\hline Cronbach alpha ${ }^{\text {a }}(N)$ & $0.882(N=927)$ & $0.796(N=966)$ \\
\hline
\end{tabular}

${ }^{\text {a } A}$ value higher than 0.7 indicates a reliable scale.

\section{References}

Berkowitz A D 2008 Reporters and their sources The Handbook of Journalism Studies ed K Wahl-Jorgensen and T Hanitzsch (New York: Routledge) pp 102-15

Besley J C, McComas K A and Trumbo C W 2012 Citizen views about public meetings J. Risk Res. $15355-71$

Covello V T 1992 Trust and credibility in risk communication Health Environ. Dig. 6 1-3

Daudey E 2015 CREDOC Report Baromètre de la Perception des Risques Sanitaires (www.credoc.fr/ pdf/Rapp/R321.pdf)

El Jammal M-H, Mur E, Rollinger F and Schuler M 2013 Baromètre IRSN La perception des Risques et de la Sécurité par les Français (Fontenay-aux-Roses: Institut de Radioprotection et de la Sûreté Nucléaire)

EU 2001 Directive 2001/42/EC of the European Parliament and of the Council of 27 June 2001 on the assessment of the effects of certain plans and programmes on the environment Official J. Eur. Commun. 197 30-7

Euratom 2013 Basic safety standards for protection against the dangers arising from exposure to ionising radiation, and repealing Directives 89/618/Euratom, 90/641/Euratom, 96/29/Euratom, 97/43/ Euratom and 2003/122/Euratom OJ L 1320143

Eurobarometer 3242010 Europeans and Nuclear Safety (Brussels: European Commission)

Fessenden-Raden J, Fitchen J M and Heath J S 1987 Providing risk information in communities: factors influencing what is heard and accepted Sci. Technol. Hum. Values 12 94-101 
Gadbois S etal 2007 Situation concerning public information about and involvement in the decision-making processes in the nuclear sector Final Report of the E.C.Contract TREN_04_NUCL_S07-39556

Hecht M L 1978 The conceptualization and measurement of interpersonal communication satisfaction Hum. Commun. Res. 4 253-64

Holbrook A L, Green M C and Krosnick J A 2003 Telephone versus face-to-face interviewing of national probability samples with long questionnaires: comparisons of respondent satisficing and social desirability response bias Public Opin. Q. 67 79-125

Laes E and Bombaerts G 2008 In de klei rijden of democratiseren? Uitdagingen voor het nucleair afvalbeheer in België Samenleving en Politiek 15 30-8

Kari M, Kojo M and Litmanen T 2010 Community Divided: Adaptation and Aversion Towards the Spent Nuclear Fuel Repository in Eurajoki and Its Neighbouring Municipalities (University of Jyväskylä/University of Tampere, Jyväskylä-Tampere, Finland) https://jyx.jyu.fi/dspace/ handle/123456789/25794

Kojo M, Kari M and Litmanen T 2010 The socio-economic and communication challenges of spent nuclear fuel management in Finland: the post site selection phase of the repository project in Eurajoki Prog. Nucl. Energy 52 168-76

Kovach B and Rosenstiel T 2007 The Elements of Journalism: What Newspeople Should Know and the Public Should Expect (New York: Three Rivers Press)

Lee C I, Haims A H, Monico E P, Brink J A and Forman H P 2004 Diagnostic CT scans. Assessment of patient, physician, and radiologist awareness of radiation dose and possible risks Radiology $231393-8$

Lichtenberg J and MacLean D 1991 The role of the media in risk communication Communicating Risks to the Public ed R E Kasperson and J M Stallen (Dordrecht: Kluwer) pp 157-75

Mays C et al 2016 Looking for citizen-centered communication: dialogues between radiological protection or nuclear safety specialists and media professionals J. Radiat. Prot. 36 S143-59

McComas K A 2003 Citizen satisfaction with public meetings used for risk communication J. Appl. Commun. Res. 31164

Nickoloff E L and Alderson P O 2001 Radiation exposures to patients from CT-reality, public perception, and policy AJR Am. J. Roentgenol. 177 285-7

OECD 2004 Stakeholder Participation in Radiological Decision Making: Processes and Implications, Case Studies for the Third Villigen Workshop (21-23 October 2003) (Paris: OECD NEA N${ }^{\circ} 5410$ )

Perko T, Thijssen P, Turcanu C and Van Gorp B 2014 Insights into the reception and acceptance of risk messages: nuclear emergency communication J. Risk Res. 17 1207-32

Perko T, van Gorp B, Turcanu C, Thijssen P and Carlé B 2013 Communication in nuclear emergency preparedness: a closer look at information reception Risk Anal. 33 1987-2001

Peters R G, Covello V T and McCallum D B 1997 The determinants of trust and credibility in environmental risk communication Risk Anal. 17 43-54

Renn O 2008 Risk Governance: Coping with Uncertainty in a Complex World (London: Earthscan)

Renn O and Levine D 1991 Credibility and trust in risk communication Communicating Risks to the Public ed R E Kasperson and P J M Stallen (Dordrecht: Kluwer) pp 175-217

Schröder J, Bergmans A and Laes E 2015 Advanced research, lagging policy: nuclear waste governance in Belgium Nuclear Waste Governance: an International Comparison (Wiesbaden: Springer) pp 141-56

Sjöberg L 2000 Perceived risk and tampering with nature J. Risk Res. 3 353-67

Sloan M, Wright D and Barrett K 2010 Phone or face-to-face? Comparing data from surveys of people with disabilities Mathematica 4 1-2

Slovic P 1987 Perception of risk Science 236 280-5

Slovic P 1993 Perceived risk, trust, and democracy Risk Anal. 13 675-82

Turcanu C and Perko T 2011 Decision making for installations with risks: who wants to be involved? 19th SRA-Europe Conf. (Society for Risk Analysis) (Stuttgart, Germany)

Turcanu C and Perko T 2014a The SCK•CEN barometer 2013-perceptions and attitudes towards nuclear technologies in the Belgian population Open Report of the Belgian Nuclear Research Centre BLG-1097 Mol, Belgium

Turcanu C and Perko T 2014b Report on Public Views across EU on Education and Information in the Post-Fukushima Context Belgian Nuclear Research Institute, SCK•CEN, Belgium (http://eagle. sckcen.be/en/Deliverables)

Turcanu C and Perko T 2014c Het nucleaire Dessel, wat denkt u erover? Een online bevraging bij de bevolking in Dessel External Report of the Belgian Nuclear Research Centre ER-253 Mol, Belgium 
Turcanu C, Perko T and Schröder J 2011 The SCK•CEN barometer 2011-perception and attitudes towards nuclear technologies in the Belgian population Open Report of the Belgian Nuclear Research Centre BLG-1082 Mol, Belgium

UNEC 1998 Convention on Access to Information, Public Participation in Decision-making and Access to Justice in Environmental Matters: Aarhus Convention (Aarhus: United Nations Economic Commision Europe)

Verkissen M N et al 2014 The role of health literacy in perceived information provision and satisfaction among women with ovarian tumors: a study from the population-based PROFILES registry Patient Educ. Couns. 95 421-8

Wilson J 1996 Understanding Journalism (New York: Routledge)

Železnik N, Constantin M, Schneider N, Mays C, Zakrzewska G and Diaconu D 2016 Lay public mental models of ionizing radiation: representations and risk perception in four European countries J. Radiat. Prot. 36 S102-21 